\title{
A three-dimensional hydrodynamic model for aquaculture: a case study in the Bay of Fundy
}

\author{
Yongsheng $\mathrm{Wu}^{1, *}$, Jason Chaffey ${ }^{1}$, Brent Law $^{2}$, David A. Greenberg ${ }^{1}$, \\ Adam Drozdowski ${ }^{2}$, Fred Page ${ }^{3}$, Susan Haigh ${ }^{3}$ \\ ${ }^{1}$ Marine Ecosystem Section, Ocean and Ecosystem Sciences Division, Fisheries and Oceans Canada, \\ Bedford Institute of Oceanography, Dartmouth, Nova Scotia B2Y 4A2, Canada \\ ${ }^{2}$ Coastal Ecosystem Sciences Division, Fisheries and Oceans Canada, Bedford Institute of Oceanography, Dartmouth, \\ Nova Scotia B2Y 4A2, Canada \\ ${ }^{3}$ Coastal Ecosystem Sciences Division, Fisheries and Oceans Canada, St. Andrews Biological Station, St. Andrews, \\ New Brunswick E5B 2L9, Canada
}

\begin{abstract}
Impacts of aquaculture on the local current field and the erosion of the bottom sediment in the Bay of Fundy, Canada, have been investigated with a 3-dimensional hydrodynamic model. The model is evaluated against independent observations of the current. Model results show that the presence of fish cages restricts water flow and reduces the velocity in the surface layer occupied by the cages, but enhances the water velocity in the bottom layer beneath the cages. Sensitivity studies show that the change in the flow velocity beneath the cages is sensitive to variations in the drag coefficient and the height of the fish cages. As the drag coefficient increases, the bottom velocity also increases until a steady state value is reached. For the cage height, however, the tidal speed beneath the cages first increases with cage height and then significantly decreases with further increasing height. The maximum increase in velocity occurs when the cage height is about half the local water depth $\left(H / H_{0}=0.5\right.$, where $H$ is the cage height and $H_{0}$ is the water depth). The increase in bottom velocity significantly speeds up the erosion of the bottom sediment. The model results also indicate that there is an optimal drag coefficient and an optimal cage height for a specific farm site. By utilizing the optimal drag coefficient and height, it is possible to speed up sediment erosion beneath the cages and, thus, decrease the environmental problems caused by accumulated fish farm waste.
\end{abstract}

KEY WORDS: Quadratic friction term · Fish farm - Sediment erosion - Finite-Volume Coastal Ocean Model · FVCOM

\section{INTRODUCTION}

Aquaculture in marine coastal waters is a rapidly growing area of sea food production in Canada (Environment Canada 2009). In southwest New Brunswick (SWNB), for example, the number of salmon aquaculture sites increased from a single site in 1978 to 92 sites in 2011 (New Brunswick Department of Agriculture, aquaculture sector in review 2011). The farmed fish are cultivated in man-made enclosures, such as cages, which are usually sus-

\footnotetext{
${ }^{*}$ Corresponding author: Yongsheng.Wu@dfo-mpo.gc.ca
}

pended in the upper layer of the water column and positioned through mooring systems fixed to the seabed. While farms produce fish, they also produce organic waste, such as faeces and uneaten feed. The waste is able to release inorganic nutrients while sinking and is deposited on the bottom sediment beneath the fish cages (Silvert \& Sowles 1996, Fernandes et al. 2007). Mineralization of the deposited waste consumes dissolved oxygen in the bottom sediment and releases inorganic nutrients, which can cause eutrophication and oxygen depletion and thus

() Fisheries and Oceans Canada 2014. Open Access under Creative Commons by Attribution Licence. Use, distribution and reproduction are unrestricted. Authors and original publication must be credited.

Publisher: Inter-Research · www.int-res.com 
influence the water quality in near-field areas (Hevia et al. 1996, Page et al. 2005, Skogen et al. 2009). The bottom sediment can be eroded and transported due to currents and waves, and the aquaculture site can thereby affect the water quality in the far-field (Gyllenhammar \& Hakanson 2005). The environmental problems caused by farming waste are known to be important factors limiting the development of aquaculture (Page et al. 2005, Giles et al. 2009, Moreno Navas et al. 2011, Sanz-Lázaro et al. 2011).

The transport of sediment from the local area of fish farms to far-field areas can be quantitatively described by hydrodynamic models coupled to sediment models. In general, hydrodynamic models are driven by atmospheric and oceanic forcing, and produce parameters, such as current velocity and mixing intensity, which are required in sediment-transport models. Several research groups have demonstrated that these models can be successfully applied to predict the footprints of the waste from fish farms in the near- or far-field waters (Panchang et al. 1997, Dudley et al. 2000, Grant \& Bacher 2001, Henderson et al. 2001, Cromey et al. 2002b, Doglioli et al. 2004, Ali et al. 2011, Moreno Navas et al. 2011). Detailed reviews of the implementations and applications of such models can be found in Cromey et al. (2002a) and Andréfouët et al. (2006).

In addition to the main forces from the ocean and atmosphere, the friction effect of the aquaculture system, for instance fish cages, could be an important factor in estimating the local current velocity in a fish farm (Inoue 1972). In general, a fish-cage system consists of an enclosed netting cage, mooring ropes and a number of accessories, such as floating collars, floats, sinkers and buoys. On the one hand, the presence of the system exerts drag forces on the flow and thus reduces the water velocity. For example, Inoue (1972) observed that fish cages damped current speed by up to $65 \%$. Such a significant reduction of the water speed was found to be important for the exchange properties of oxygen and waste transport inside cages (Fredriksson et al. 2007). On the other hand, the flowing water exerts a force on the cage system, which can be an important factor for cage design (Fredriksson et al. 2003, Rasmussen \& McLean 2004, Fredriksson et al. 2007, Huang et al. 2008, Lee et al. 2008, DeCew et al. 2010, Dong et al. 2010). Previous studies have generally ignored the effect of the aquaculture system when investigating hydrodynamic processes and sediment transport in culture farms using circulation models, except for a few, e.g. Grant \& Bacher (2001), who accounted for the resistance effect of suspended aquaculture by adding extra drag in a depth-averaged tidal model. In their 2-dimensional (2-D) model, the effect of culture was applied throughout the whole water column. They found that the current speed could be reduced by $50 \%$ due to the barrier of the suspended aquaculture. They concluded that a 2-D model ignoring the effect of the culture could seriously overestimate the carrying capacity of an aquaculture farm.

In the present study, the effect of aquaculture is included in a 3-D tidal model by adding an extra drag term in the standard momentum equations. In the 3-D model, the effect of fish cages can be applied at arbitrary levels in the vertical direction. Compared to a depth-averaged 2-D model, a 3-D model is more realistic when the aquaculture only occupies part of the water column. In such cases, the current velocity in the subsurface layer, where the aquaculture is absent, is hard to simulate in a 2-D model. The focus of this study is mainly on changes in tidal currents in the overall farm. The changes caused by a single cage, however, are beyond the scope of this investigation.

\section{METHODS}

\section{Study area and model setup}

The study area is the Bliss Harbour fish farm located in the southwest isles region of New Brunswick, Canada (Fig. 1). The area of the farm is $347 \times$ $117 \mathrm{~m}$, roughly $40.6 \times 10^{3} \mathrm{~m}^{2}$, including 2 rows of salmon cages and 1 row of mussel cages. The salmon cages are $32 \mathrm{~m}$ in diameter and the mussel cages are $22 \mathrm{~m}$ in diameter. The spacing between the salmon cages is $13 \mathrm{~m}$ and that between the mussel cages is $23 \mathrm{~m}$.

The model used in this study is the Finite-Volume Coastal Ocean Model (FVCOM), which is a 3-D, finite-volume, unstructured grid ocean model developed at the University of Massachusetts-Dartmouth (Chen et al. 2003, 2007, Cowles et al. 2008). FVCOM has a free surface, uses sigma coordinates in the vertical and employs mode time split technology. The model also contains an embedded second-order turbulence closure scheme and uses a Smagorinsky diffusivity to estimate horizontal diffusion processes. To simulate the flooding/drying processes, a massconserving wet/dry point treatment is employed in the model. FVCOM uses an unstructured triangle mesh system, which is flexible for different spatial scales of the hydrodynamic processes, for instance the current field in a fish farm in this study. To date, 


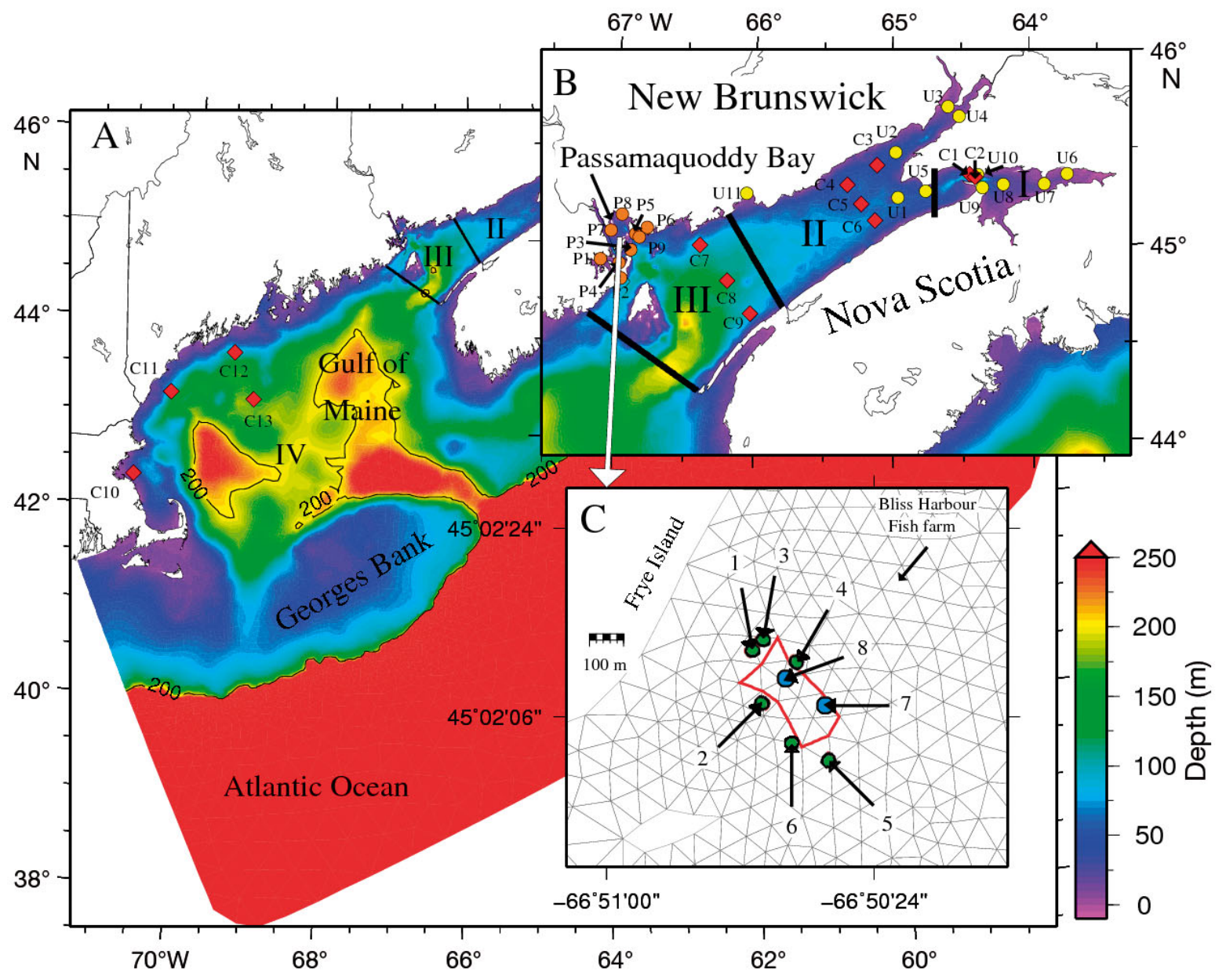

Fig. 1. (A) Model domain, (B) the Bay of Fundy and (C) mesh in the study area. (A, B) Locations of (O) tidal level data in the upper Bay of Fundy (U1 to U11), (O) tidal level data in Passamaquoddy Bay (P1 to P9), and ( $\diamond$ ) current data used in Table 3 (C1 to C13). I, II, III and IV stand for the upper Bay of Fundy, lower Bay of Fundy, outer Bay of Fundy and Gulf of Maine, respectively. (C) Locations of the moored acoustic Doppler current profilers (nos. 1 to 8) are shown, including those at the (O) edge and (O) interior of the farm (red outline)

FVCOM has become a fully coupled iceocean-wave-sediment-ecosystem model system and has been used for various purposes covering a great variety of scales in time and space (Gao et al. 2011). The model domain covers the Scotian Shelf, Georges Bank, Gulf of Maine and the Bay of Fundy (Fig. 1). The initial coastline and bathymetric data were obtained from a digital version of a Canadian Hydrographic Service nautical chart. Recent multi-beam sonar data were used to supplement the bathymetry in the upper Bay of Fundy. The model mesh has 43055 nodes and 79082 triangular elements, and the horizontal resolution of the elements varies from $10 \mathrm{~s}$ of $\mathrm{km}$ in the outer part of the model domain to about $20 \mathrm{~m}$ in
Table 1. Observed and modelled amplitude and phase, and discrepancies of $\mathrm{M}_{2}$ tidal elevations in the upper Bay of Fundy (locations of the sites are shown in Fig. 1B)

\begin{tabular}{|c|c|c|c|c|c|c|c|}
\hline \multirow{2}{*}{ Station } & \multicolumn{2}{|c|}{ Observed } & \multicolumn{2}{|c|}{ Modelled } & \multicolumn{2}{|c|}{ Difference } & \multirow{2}{*}{$\begin{array}{c}\text { Error } \\
(\mathrm{m})\end{array}$} \\
\hline & $\underset{(\mathrm{m})}{\mathrm{Ampl}}$ & $\begin{array}{c}\text { Phase } \\
\left({ }^{\circ}\right)\end{array}$ & $\underset{(\mathrm{m})}{\text { Ampl. }}$ & $\begin{array}{c}\text { Phase } \\
\left({ }^{\circ}\right)\end{array}$ & $\underset{(\mathrm{m})}{\text { Ampl. }}$ & $\begin{array}{c}\text { Phase } \\
\left({ }^{\circ}\right)\end{array}$ & \\
\hline U1 & 4.15 & 99.2 & 4.10 & 101.0 & -0.05 & 1.8 & 0.13 \\
\hline U2 & 4.26 & 104.2 & 4.20 & 102.7 & -0.06 & -1.5 & 0.13 \\
\hline U3 & 4.86 & 104.4 & 4.74 & 105.8 & -0.12 & 1.4 & 0.16 \\
\hline U4 & 4.74 & 104.6 & 4.75 & 104.6 & 0.01 & 0.0 & 0.02 \\
\hline U5 & 4.34 & 102.0 & 4.41 & 107.0 & 0.07 & 5.0 & 0.38 \\
\hline U6 & 6.12 & 129.3 & 6.30 & 128.8 & 0.18 & -0.5 & 0.19 \\
\hline U7 & 5.92 & 125.4 & 6.07 & 122.6 & 0.15 & -2.8 & 0.33 \\
\hline U8 & 5.54 & 120.8 & 5.63 & 117.4 & 0.09 & -3.4 & 0.35 \\
\hline U9 & 5.36 & 116.7 & 5.38 & 113.8 & 0.02 & -2.9 & 0.27 \\
\hline U10 & 5.17 & 117.0 & 5.25 & 116.5 & 0.08 & -0.5 & 0.10 \\
\hline U11 & 3.04 & 98.2 & 2.97 & 99.3 & -0.07 & 1.1 & 0.08 \\
\hline Mean & 4.86 & - & 4.89 & - & 0.03 & -0.2 & 0.19 \\
\hline $\mathrm{rms}$ & - & - & - & - & 0.10 & 2.5 & 0.12 \\
\hline
\end{tabular}


the study area. There are 21 levels in the vertical, with enhanced resolution near the surface and bottom. The model was forced by the tidal elevation of the 5 largest constituents $\left(\mathrm{M}_{2}, \mathrm{~N}_{2}, \mathrm{~S}_{2}, \mathrm{~K}_{1}\right.$ and $\left.\mathrm{O}_{1}\right)$ derived from Web Tide, a software package for tidal prediction (Dupont et al. 2002). The time step is $0.8 \mathrm{~s}$. The model runs for $35 \mathrm{~d}$ from still water for spin up and then runs for $29 \mathrm{~d}$ for model validation and model results analysis with the hourly model output. Default values are used for all the parameters in the model runs except bottom roughness, which is derived from the observed grain size data described by $\mathrm{Wu}$ et al. (2011). The bottom sediment at the farm site is composed almost entirely of mud $(<63 \mu \mathrm{m})$ with a small sand fraction of 1 to $2 \%$. The fraction of clay $(<4 \mu \mathrm{m})$ is about 20 to $30 \%$. The majority of the settling of this fine-grained material occurs in flocs. A series of sensitivity tests indicated that the variable roughness improved the model performance, especially for the tidal levels and currents in the upper Bay of Fundy, but the details of the sensitivity study are not given here since they are beyond the scope of this paper.

\section{Model validation}

Tidal elevation comparisons

The model-data comparison of tidal levels mainly focuses on 2 areas. One is the upper Bay of Fundy, which is well known for high tides, and the other is Passamaquoddy Bay, where the aquaculture farm is located. The results of the comparison of tidal amplitudes and phases of the $\mathrm{M}_{2}$ constituent, the dominant

Table 2. Observed and modelled amplitude and phase, and discrepancies of $\mathrm{M}_{2}$ tidal elevations in Passamaquoddy Bay (locations of the sites are shown in Fig. 1B)

\begin{tabular}{|c|c|c|c|c|c|c|c|}
\hline \multirow[t]{2}{*}{ Station } & \multicolumn{2}{|c|}{ Observed } & \multicolumn{2}{|c|}{ Modelled } & \multicolumn{2}{|c|}{ Difference } & \multirow{2}{*}{$\begin{array}{c}\text { Error } \\
(\mathrm{m})\end{array}$} \\
\hline & $\underset{(\mathrm{m})}{\text { Ampl. }}$ & $\begin{array}{c}\text { Phase } \\
\left({ }^{\circ}\right)\end{array}$ & $\begin{array}{c}\text { Ampl. } \\
(\mathrm{m})\end{array}$ & $\begin{array}{c}\text { Phase } \\
\left({ }^{\circ}\right)\end{array}$ & $\underset{(\mathrm{m})}{\text { Ampl. }}$ & $\begin{array}{c}\text { Phase } \\
\left({ }^{\circ}\right)\end{array}$ & \\
\hline $\mathrm{P} 1$ & 2.69 & 104.3 & 2.64 & 104.9 & -0.05 & 0.6 & 0.05 \\
\hline $\mathrm{P} 2$ & 2.17 & 95.1 & 2.28 & 97.6 & 0.11 & 2.5 & 0.15 \\
\hline P3 & 2.48 & 95.6 & 2.46 & 97.5 & -0.02 & 1.9 & 0.08 \\
\hline $\mathrm{P} 4$ & 2.63 & 97.6 & 2.54 & 100.3 & -0.09 & 2.7 & 0.15 \\
\hline P5 & 2.66 & 100.5 & 2.48 & 97.2 & -0.18 & -3.3 & 0.23 \\
\hline P6 & 2.60 & 97.9 & 2.49 & 97.5 & -0.11 & -0.4 & 0.12 \\
\hline P7 & 2.72 & 106.5 & 2.60 & 103.8 & -0.12 & -2.7 & 0.18 \\
\hline P8 & 2.72 & 106.2 & 2.61 & 103.8 & -0.11 & -2.4 & 0.16 \\
\hline P9 & 2.63 & 94.5 & 2.47 & 97.3 & -0.16 & 2.8 & 0.20 \\
\hline Mean & 2.59 & & 2.51 & & -0.08 & 0.2 & 0.15 \\
\hline $\mathrm{rms}$ & & & & & 0.09 & 2.5 & 0.06 \\
\hline
\end{tabular}

tidal constituent, at 11 tidal stations in the upper Bay of Fundy (their locations are shown in Fig. 1B) are listed in Table 1. The modelled results agree well with their observed counterparts. For example, the amplitude differences range from -0.12 to $0.18 \mathrm{~m}$, and the mean difference is $0.03 \mathrm{~m}$, which is less than $1.0 \%$ of the observed mean of $4.86 \mathrm{~m}$. The phase differences range from $-3.4^{\circ}$ to $5.0^{\circ}$ with a mean of $-0.2^{\circ}$, which corresponds to a half minute earlier than the observations. The root-mean-squares (rms) of the amplitude and the phase differences are $0.1 \mathrm{~m}$ and $2.5^{\circ}$, respectively. The errors, defined as the magnitudes of the vector difference between model and observation at each station, vary from 0.02 to $0.38 \mathrm{~m}$ with a mean of $0.19 \mathrm{~m}$ and a variability of $0.12 \mathrm{~m}$.

In Passamaquoddy Bay, 9 tidal gauge sites were selected (see their locations in Fig. 1B), and the results are compared in Table 2. Similar to the upper Bay of Fundy, the model results are in good agreement with the observations. The mean amplitude of the tide from the model is $0.08 \mathrm{~m}$ lower than the observed value, or $3.1 \%$ of the mean value of $2.59 \mathrm{~m}$. The mean difference of phase is comparable with that in the upper Bay of Fundy, but the direction is opposite. The errors vary from 0.05 to $0.23 \mathrm{~m}$ with a mean value of $0.15 \mathrm{~m}$ and a variability of $0.06 \mathrm{~m}$.

\section{Tidal current comparisons}

Modelled tidal currents were evaluated against observations collected at 13 sites, which are distributed in 4 regions. From east to west, these regions are upper Bay of Fundy (I), middle Bay of Fundy (II), lower Bay of Fundy (III) and Gulf of Maine (IV) (see the regions in Fig. 1A,B). The depth resolution is dense at the sites in the upper Bay of Fundy, where the observed current data are uniformly distributed with a vertical bin of $2 \mathrm{~m}$ from the surface to 7.5 $\mathrm{m}$ above the bottom. However, the vertical resolution of the sites is poor in the Gulf of Maine, where there are only a couple of depth levels available. For comparison, the model results are linearly interpolated at the observed depths. Comparisons of the depth-averaged results for $\mathrm{M}_{2}$ ellipse parameters are listed in Table 3.

In the upper Bay of Fundy (Region I), 2 sites (C1 and C2) located in the Minas Passage are used. The modelled magnitudes of depth-averaged current of the 
Table 3. Model data comparisons of depth-averaged tidal ellipse parameters of $\mathrm{M}_{2}$ (locations of the sites are shown in Fig. 1A,B)

\begin{tabular}{|c|c|c|c|c|c|c|c|c|c|c|c|c|c|}
\hline \multirow{2}{*}{ Region } & \multirow{2}{*}{ Station } & \multicolumn{4}{|c|}{$\longrightarrow$ Observed } & \multicolumn{4}{|c|}{ Modelled $\longrightarrow$} & \multicolumn{4}{|c|}{ —Difference } \\
\hline & & $\begin{array}{l}\text { Semi- } \\
\text { major } \\
\left(\mathrm{m} \mathrm{s}^{-1}\right)\end{array}$ & $\begin{array}{l}\text { Semi- } \\
\text { minor } \\
\left(\mathrm{m} \mathrm{s}^{-1}\right)\end{array}$ & $\begin{array}{c}\text { Inclina- } \\
\text { tion } \\
\left(^{\circ}\right)\end{array}$ & $\begin{array}{c}\text { Phase } \\
\left(^{\circ}\right)\end{array}$ & $\begin{array}{l}\text { Semi- } \\
\text { major } \\
\left(\mathrm{m} \mathrm{s}^{-1}\right)\end{array}$ & $\begin{array}{l}\text { Semi- } \\
\text { minor } \\
\left(\mathrm{m} \mathrm{s}^{-1}\right)\end{array}$ & $\begin{array}{c}\text { Inclina- } \\
\text { tion } \\
\left(^{\circ}\right)\end{array}$ & $\begin{array}{c}\text { Phase } \\
\left({ }^{\circ}\right)\end{array}$ & $\begin{array}{l}\text { Semi- } \\
\text { major } \\
\left(\mathrm{m} \mathrm{s}^{-1}\right)\end{array}$ & $\begin{array}{l}\text { Semi- } \\
\text { minor } \\
\left(\mathrm{m} \mathrm{s}^{-1}\right)\end{array}$ & $\begin{array}{c}\text { Inclina- } \\
\text { tion } \\
\left(^{\circ}\right)\end{array}$ & $\begin{array}{c}\text { Phase } \\
\left({ }^{\circ}\right)\end{array}$ \\
\hline \multirow[t]{2}{*}{ I } & $\mathrm{C} 1$ & 2.70 & -0.03 & 158.8 & 210.6 & 2.53 & -0.03 & 161.2 & 210.6 & -0.17 & 0 & 2.4 & 0 \\
\hline & $\mathrm{C} 2$ & 2.87 & -0.10 & 162.0 & 209.3 & 2.96 & -0.07 & 166.1 & 212.7 & 0.09 & 0.03 & 4.1 & 3.4 \\
\hline \multirow[t]{4}{*}{ II } & $\mathrm{C} 3$ & 0.73 & 0.03 & 30.1 & 18.3 & 0.80 & 0.01 & 34.6 & 16.5 & 0.08 & -0.02 & 4.5 & -1.8 \\
\hline & $\mathrm{C} 4$ & 0.89 & 0 & 29.0 & 20.0 & 0.92 & 0.03 & 34.8 & 17.1 & 0.03 & 0.03 & 5.8 & -2.9 \\
\hline & C5 & 1.09 & 0.05 & 31.1 & 21.9 & 1.06 & 0.02 & 32.5 & 20.2 & -0.03 & -0.03 & 1.4 & -1.7 \\
\hline & C6 & 1.04 & 0.02 & 38.1 & 20.7 & 1.15 & 0.03 & 30.9 & 24.4 & 0.11 & 0.01 & -7.2 & 3.7 \\
\hline \multirow[t]{3}{*}{ III } & $\mathrm{C} 7$ & 0.72 & 0.10 & 26.2 & 25.8 & 0.58 & 0.05 & 29.3 & 20.0 & -0.14 & -0.05 & 3.1 & -5.8 \\
\hline & C8 & 0.98 & 0.11 & 37.4 & 20.8 & 0.75 & -0.02 & 40.5 & 13.3 & -0.23 & -0.13 & 3.1 & -7.5 \\
\hline & $\mathrm{C} 9$ & 1.09 & 0.13 & 22.1 & 16.8 & 0.97 & -0.03 & 37.5 & 8.1 & -0.12 & -0.16 & 15.4 & -8.7 \\
\hline \multirow[t]{4}{*}{ IV } & C10 & 0.04 & 0 & 6.7 & 199.4 & 0.09 & 0.01 & 5.0 & 201.8 & 0.05 & 0.01 & -1.7 & 2.4 \\
\hline & C11 & 0.04 & 0.02 & 96.1 & 338.1 & 0.06 & 0.02 & 103.2 & 353.8 & 0.02 & 0 & 7.1 & 15.6 \\
\hline & $\mathrm{C} 12$ & 0.06 & 0.03 & 65.9 & 1.8 & 0.07 & 0.03 & 78.7 & 7.4 & 0.01 & 0 & 12.8 & 5.6 \\
\hline & C13 & 0.11 & 0.04 & 121.8 & 17.8 & 0.11 & 0.04 & 103.3 & 11.4 & 0 & 0 & -18.5 & -6.4 \\
\hline $\begin{array}{l}\text { Mean } \\
\text { rms }\end{array}$ & & 0.95 & 0.03 & & & 0.93 & 0.01 & & & $\begin{array}{r}-0.02 \\
0.11\end{array}$ & $\begin{array}{r}-0.02 \\
0.06\end{array}$ & $\begin{array}{l}2.5 \\
8.5\end{array}$ & $\begin{array}{r}-0.3 \\
6.7\end{array}$ \\
\hline
\end{tabular}

$\mathrm{M}_{2}$ constituent reaches $2.53 \mathrm{~m} \mathrm{~s}^{-1}$ at Site $\mathrm{C} 1$, and 2.96 $\mathrm{m} \mathrm{s}^{-1}$ at $\mathrm{C} 2$, which are in good agreement with the observed speeds of 2.70 and $2.87 \mathrm{~m} \mathrm{~s}^{-1}$, respectively. The modelled result is $0.17 \mathrm{~m} \mathrm{~s}^{-1}$ weaker than the observed current at $\mathrm{C} 1$ but $0.09 \mathrm{~m} \mathrm{~s}^{-1}$ stronger at $\mathrm{C} 2$, corresponding to $-6.3 \%$ and $+3.0 \%$ of the observed values, respectively. The modelled values of the semi-minor axis at the 2 sites are -0.03 and $-0.10 \mathrm{~m}$ $\mathrm{s}^{-1}$, which agree well with the observed values of -0.03 and $-0.10 \mathrm{~m} \mathrm{~s}^{-1}$. The modelled inclinations at the 2 sites are $161^{\circ}$ and $166^{\circ}$, slightly larger than the observed values of $159^{\circ}$ and $162^{\circ}$. The modelled phases are slightly delayed compared to their observed counterparts by $0.1^{\circ}$ and $3.4^{\circ}$, respectively.

There are 4 sites (C3 to $\mathrm{C} 6$ ) in the lower Bay of Fundy (Region II). Here, the mean observed magnitude of $\mathrm{M}_{2}$ tidal velocity is about $0.9 \mathrm{~m} \mathrm{~s}^{-1}$, which is only $30 \%$ of that in the Minas Passage. The modelled semi-major axis varies from 0.80 to $1.15 \mathrm{~m} \mathrm{~s}^{-1}$, deviating from the observed values by -0.03 to $0.11 \mathrm{~m} \mathrm{~s}^{-1}$. From Table 3, we can see that the observed tidal speed increases from north to south, and a similar spatial feature can also be seen in the model results. Both the modelled and the observed semi-minor axes are positive. The modelled inclination angles are larger than the observed angles at all of the sites in this region except $\mathrm{C} 6$, where the model result is $7.2^{\circ}$ smaller than the observed value. The modelled phases lead the observed phases at all sites except C6, where the modelled phase lags by $3.7^{\circ}$.

There are 3 sites ( $\mathrm{C} 7$ to $\mathrm{C} 9$ ) available for the comparison in Region III (the outer Bay of Fundy). Similar to Region II, tidal speed increases from north to south in Region III, and this feature can be found in both the model results and the observations. The modelled speeds are in general 10 to $20 \%$ slower than the observations. The model fails to get the observed directions of the minor axes at Sites C8 and C9. The model inclination results of are 3.1 to $15.4^{\circ}$ larger than the observed values, but the phase results are 5.8 to $8.7^{\circ}$ smaller.

Tidal currents at 4 sites (C10 to C13) in the Gulf of Maine (Region IV) are generally weaker than those in the Bay of Fundy. The modelled tidal speeds are also generally stronger than the observed speeds. Fortunately, the modelled signs of the semi-minor axis are consistent with the observations, and the magnitudes are close to the observed values as well. The differences in inclination between model and observations are relatively large, ranging from -18.5 to $12.8^{\circ}$, and the differences in phase range from -6.4 to $15.6^{\circ}$.

\section{Fish cage simulation}

\section{Model implementation}

To simulate the presence of fish cages in flowing water, an extra friction term was added to the standard momentum equations. The friction term was parameterized as the function of a drag coefficient, the tidal speed and the cage height. This method has been used previously by Hasegawa et al. (2011), who 


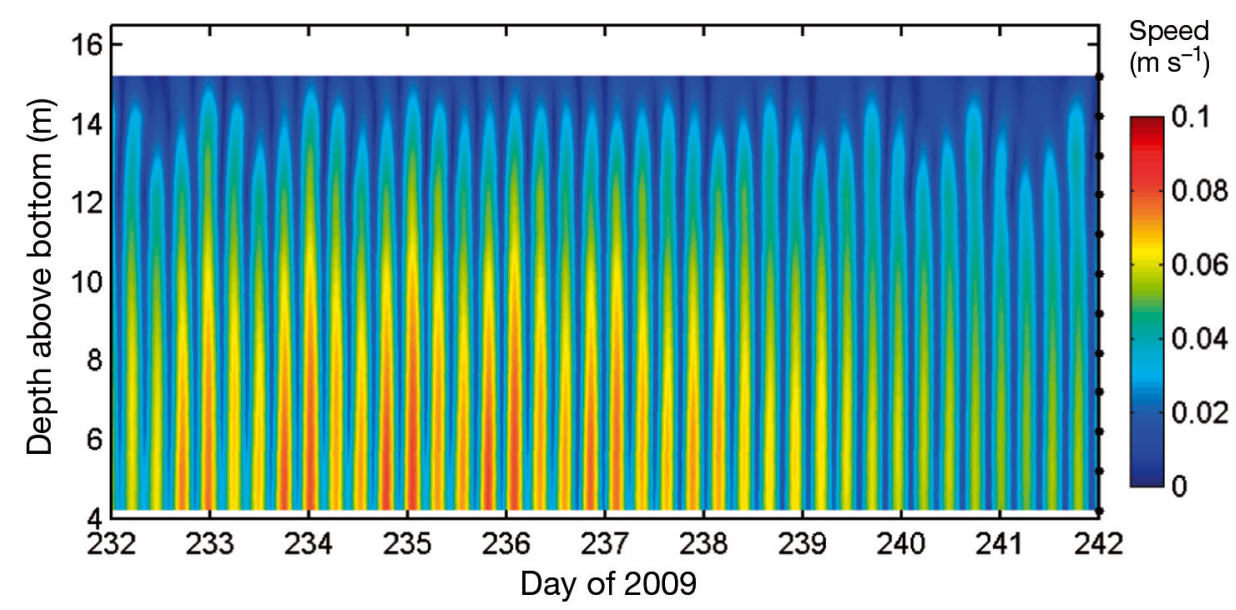

As an example, a time series of the vertical distri-

investigated the kinetic energy extraction of instream turbines from tidal currents. The momentum equation with the friction term is expressed as:

$$
\frac{\mathrm{D} u}{\mathrm{D} t}=-\frac{1}{\rho} \nabla p-2 \Omega \times u+F_{\mathrm{r}}-g(z) \cdot \lambda|u| u
$$

where the last term on the right-hand side represents the friction term, which is a function of the tidal velocity, $u$, and the drag coefficient, $\lambda$, with a unit of $\mathrm{m}^{-1}, g(z)$ is a step function which is equal to unity from the free surface to the water depth with the cage height ( $H$, unit is $\mathrm{m}$ ) and zero otherwise. Also, $t$ is time, $\rho$ is sea water density $\left(1025 \mathrm{~kg} \mathrm{~m}^{-3}\right), p$ is pressure, $F_{\mathrm{r}}$ is the horizontal and vertical diffusion term, and $2 \Omega \times u$ is the Coriolis acceleration. It is worth noting that the treatment of the friction term is based on the model elements in the horizontal and in the sigma levels in the vertical.

\section{Observed current data}

To accompany the development of the hydrodynamic model for the aquaculture study in the fish farm at Bliss Harbour, 8 moored acoustic Doppler current profilers (ADCP) were deployed in August 2009 (Fig. 1C). Two moorings were located in the interior of the farm and the remaining 6 were located at the edge of the farm. In this study, 4 sites are used to calibrate the drag coefficient, and the remaining 4 are used for the model validation. For each mooring, there are 6 to 10 depth levels distributed from $4 \mathrm{~m}$ above the seabed with a $2 \mathrm{~m}$ bin interval. The duration of the data records varies from 28 to $41 \mathrm{~d}$. Before using the data, bins that were clearly above the highest observed water levels were discarded. Small gaps $(<30 \mathrm{~min})$ in the time series were linearly interpolated to give complete records (gaps less than $1 \%$ for all intertidal bins). butions of the tidal speed derived from the raw data with the tidal analysis package $T_{-}$Tide (Pawlowicz et al. 2002) at Site 6 (Fig. 1C) are plotted in Fig. 2. One significant feature of the observations is that the tidal speed in the upper layer ( $>10 \mathrm{~m}$ above the seabed) is clearly slower than that in the lower layer. This vertical feature is consistent throughout the observation period. For example, during Days 234 to 237 of 2009, the tidal speed in the bottom layer ( 4 to $10 \mathrm{~m}$ above the bottom) reaches $0.1 \mathrm{~m} \mathrm{~s}^{-1}$, which is 4 to 5 times higher than that in the upper layer. Similar speed distributions in the vertical direction were found at other sites but with different magnitudes.

\section{Drag coefficient calibration}

Theoretically, the drag coefficient of a fish cage is related to many factors, such as the mesh size and shape, mesh type and material, degree of fouling, stocking density and the intensity of currents passing through it (Beveridge 1984). Thus, the drag coefficient is not a constant. For this preliminary study,

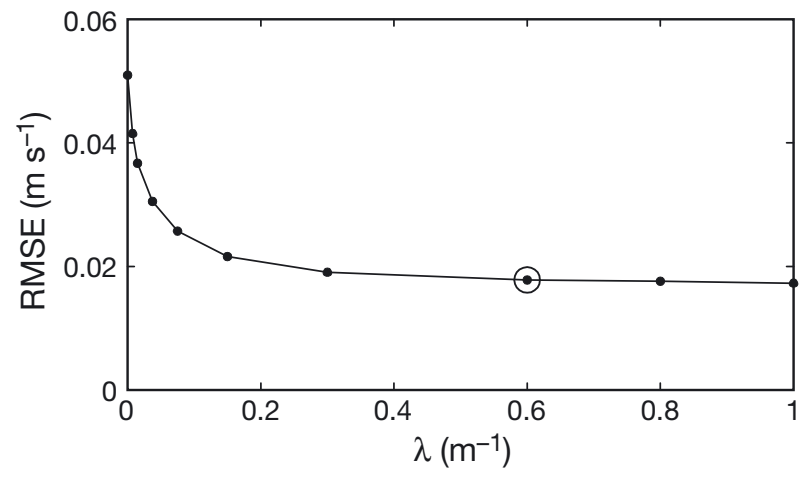

Fig. 3. Relation of root mean square error (RMSE) to drag coefficient of cages $(\lambda)$.(O) $\lambda=0.6 \mathrm{~m}^{-1}$ 
however, for simplicity, we assume that the drag coefficient has a constant value, independent of space and time. The height of the fish cages is $10 \mathrm{~m}$. Since a direct test of the drag caused by a fish cage is not available, a trial and error method was used to achieve the value of the constant in this investigation by comparing the modelled currents against their in situ counterparts collected at Sites 1 to 4 with moored $\mathrm{ADCP}$ in the fish farm. The root mean square error (RMSE) between the magnitudes of the modelled and observed $\mathrm{M}_{2}$ tidal speeds is defined as:

$$
\operatorname{RMSE}=\sqrt{\frac{\sum_{i=1}^{n}\left(U_{\mathrm{mod}, i}-U_{\mathrm{obs}, \mathrm{i}}\right)^{2}}{n}}
$$

where $n$ is the sample number ( $n=12$ for 3 depth levels, 12,8 and $4 \mathrm{~m}$ above the seabed, at 4 sites), $U_{\bmod }$ and $U_{\text {obs }}$ are the magnitudes of the modelled and observed $\mathrm{M}_{2}$ tidal speeds, respectively. The change in the RMSE as the drag coefficient varies from 0 to $1.0 \mathrm{~m}^{-1}$ is shown in Fig. 3. As the drag coefficient increases, the RMSE decreases. The value of RMSE varies from $0.052 \mathrm{~m} \mathrm{~s}^{-1}$ at $\lambda=0$ to $0.02 \mathrm{~m} \mathrm{~s}^{-1}$ at $\lambda=$ $1.0 \mathrm{~m}^{-1}$. Theoretically, 1.0 should be selected, since

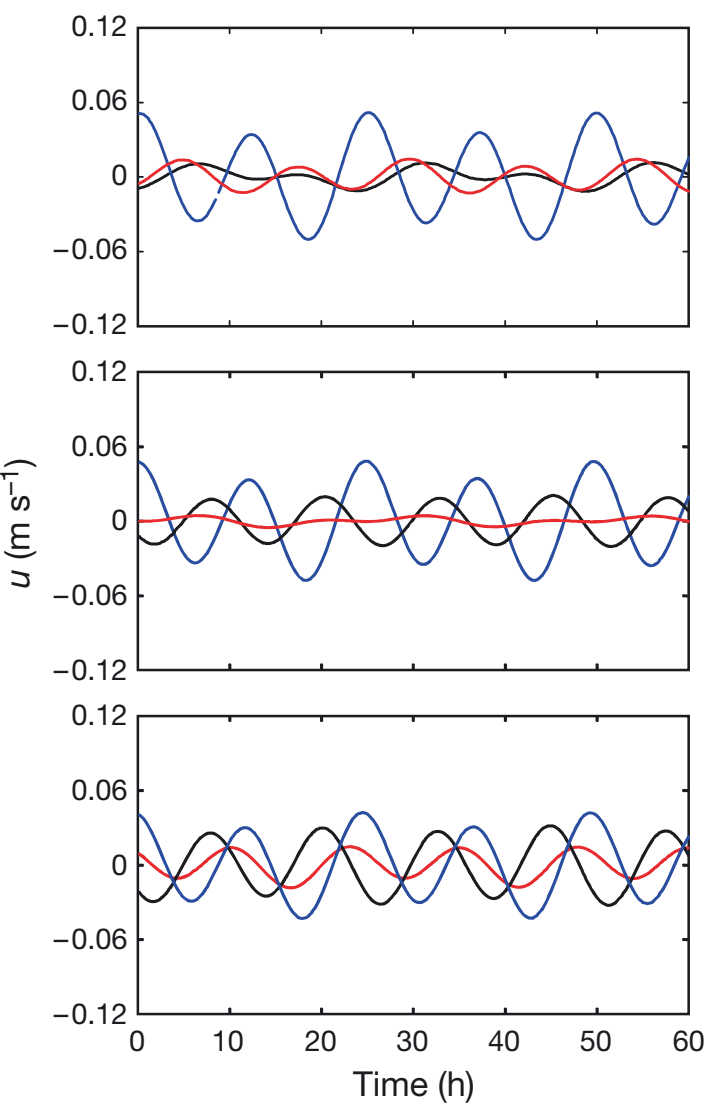

the minimum RMSE is smaller. However, a bigger drag coefficient will cause a stronger impact on the local current field. We recognized that the decrease rate of the RMSE becomes negligible when $\lambda>$ $0.6 \mathrm{~m}^{-1}$. So, this value was set as the default drag coefficient used in the model run.

\section{Model validation}

Based on the preferred drag coefficient, the model was evaluated against independent observations collected at Sites 5 to 8 in the aquaculture farm. The modelled velocities were linearly interpolated at the observation sites. In order to show the efficiency of the method, the model results from the case without the cage effect were also compared.

As an example, comparisons between modelled tidal current components $u$ and $v(u$ and $v$ are velocity in the east and north directions) and their observed counterparts at Site 6 are shown in Fig. 4. The comparisons indicate that the currents modelled with the cage effect are clearly better than those without
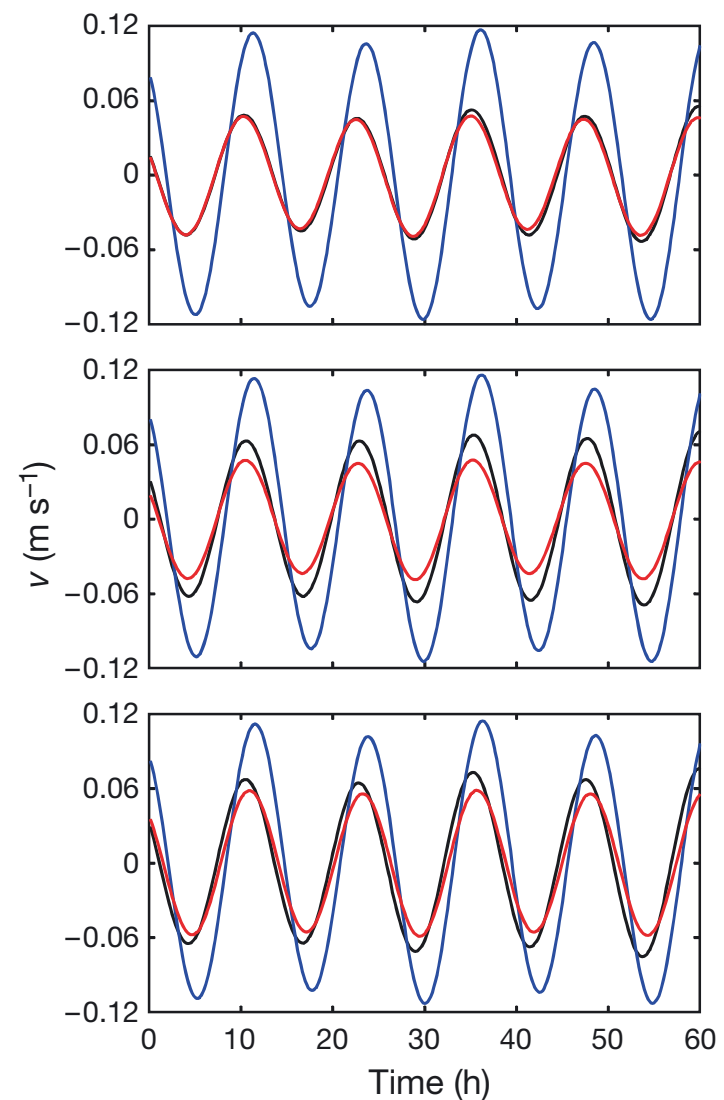

Fig. 4. Time-series comparisons of tidal velocity components $u$ (left) and $v$ (right) between (black) observations, model results obtained without (blue) and with cage effect (red) at Site 6 (for location see Fig. 1C) at selected depth levels of 12 (upper), 8 (middle), and $4 \mathrm{~m}$ (lower) above the seabed 
at all 3 depth levels, including both the amplitudes and the phases, especially for the current component $V$, which dominates the tidal speeds. Using a statistical approach, the harmonic constants of $\mathrm{M}_{2}$ were compared and the results are listed in Table 4. We can see that the results obtained with the cage effect are in good agreement with the observations. Performance of the model with the cage effect is clearly better than that without. With the cage effect, the modelled averaged $u$ and $v$ velocity amplitudes (unit is $10^{-2} \mathrm{~m} \mathrm{~s}^{-1}$ ) at the 4 sites at all the mooring sites at 3 depth levels are 1.3, 1.3 and 2.6, and 2.4, 2.6 and 4.8 , respectively, which consistently agree with the observations of 1.6, 2.1 and 2.4, and 3.0, 4.3 and 4.6. However, the corresponding averaged velocities without the cage effect are 3.9, 3.9 and 3.7, and 7.4, 7.4 and 7.4 , which are about 2 times greater than the observed velocities. Both the model results with the cage effect and the observations show that the tidal speeds increase from surface to bottom. However, this vertical distribution feature is not found in the model results obtained in the absence of the cage effect. The simulated phases of the velocities are also improved when the cage effect is included. The harmonic constants for other tidal constituents were also compared and the comparison shows that the model results are improved when the effect of the fish cages is included. The results are not shown here because the amplitudes of other constituents are smaller than those of $\mathrm{M}_{2}$ by nearly an order of magnitude.

\section{RESULTS}

In this section, we will discuss how the tidal currents change under the effects of cages in the whole water column and in the horizontal directions. To show the vertical variations, model results for 2 mooring sites (6 and 8) are presented. One is at the edge of the fish farm, and the other is in the interior of the farm (see the locations in Fig. 1C). Without the cage effect, the modelled tidal speed at the edge shows a clear flood-ebb cycle, and the magnitude of the velocity on the ebb is 1 to 2 times greater than that in flood (Fig. 5A). The tidal speed, however, shows little variation in the vertical direction (Fig. 5A). In contrast, including the effect of the fish cages increases the variation in the tidal speed distributions in the vertical direction. One significant difference is that the magnitude of the tidal velocity in the upper surface layer (approx. $0-10 \mathrm{~m}$ ) is 2 to 3 times smaller than that without the cage effect (Fig. 5B). This is understandable because the friction of the cages consumes the kinetic energy of the flowing water and thus decreases the tidal speed.

Similarly to the site at the edge of the fish farm, the modelled tidal speed in the interior of the farm decreases in the surface layer due to the effect of the fish cages (Fig. 5D). In the bottom layer (within $1 \mathrm{~m}$ above the seabed), the velocity is clearly faster than in the model without cage influence (Fig. 5C), ranging from 0.05 to $0.1 \mathrm{~m} \mathrm{~s}^{-1}$. We can see that the

Table 4. Model validation. Comparisons of $\mathrm{M}_{2}$ currents from moored acoustic Doppler current profilers (Obs) with model results with and without cage effect (locations of the sites are shown in Fig. 1C). Diff.: difference. $u$ and $v$ are velocity in the east and north directions, $\mathrm{Am}\left(10^{-2} \mathrm{~m} \mathrm{~s}^{-1}\right)$ and $\mathrm{Ph}\left(^{\circ}\right)$ stand for amplitude and phase, respectively, and $Z$ is the distance from the seabed (m)

\begin{tabular}{|c|c|c|c|c|c|c|c|c|c|c|c|c|c|c|c|c|c|c|c|c|c|}
\hline \multicolumn{2}{|c|}{ Mooring } & \multicolumn{4}{|c|}{$\longrightarrow$ Obs } & \multicolumn{4}{|c|}{$\longrightarrow$ Cage -} & \multicolumn{4}{|c|}{- No cage -} & \multicolumn{4}{|c|}{ Diff. (Cage - Obs) } & \multicolumn{4}{|c|}{ Diff. (No cage - Obs) } \\
\hline \multirow{2}{*}{ No. } & \multirow[t]{2}{*}{$Z$} & \multicolumn{2}{|c|}{$u$} & \multicolumn{2}{|c|}{ V } & \multicolumn{2}{|c|}{$u$} & \multicolumn{2}{|c|}{ V } & \multicolumn{2}{|c|}{$u$} & \multicolumn{2}{|c|}{ V } & \multicolumn{2}{|c|}{$u$} & \multicolumn{2}{|c|}{ V } & \multicolumn{2}{|c|}{$u$} & \multicolumn{2}{|c|}{ V } \\
\hline & & $\mathrm{Am}$ & $\mathrm{Ph}$ & $\mathrm{Am}$ & $\mathrm{Ph}$ & $\mathrm{Am}$ & $\mathrm{Ph}$ & $\mathrm{Am}$ & $\mathrm{Ph}$ & $\mathrm{Am}$ & $\mathrm{Ph}$ & $\mathrm{Am}$ & $\mathrm{Ph}$ & Am & $\mathrm{Ph}$ & Am & $\mathrm{Ph}$ & Am & $\mathrm{Ph}$ & $\mathrm{Am}$ & $\mathrm{Ph}$ \\
\hline \multirow[t]{3}{*}{5} & 12 & 3.6 & 328 & 4.6 & 331 & 3.6 & 324 & 4.6 & 335 & 3.6 & 6 & 7.5 & 343 & 0 & -4 & -0.1 & 4 & 0 & 38 & 2.8 & 12 \\
\hline & 8 & 3.7 & 328 & 4.9 & 335 & 3.7 & 319 & 5.2 & 340 & 3.7 & 359 & 7.6 & 344 & 0 & -9 & 0.3 & 5 & 0 & 31 & 2.7 & 10 \\
\hline & 4 & 3.3 & 319 & 5.1 & 333 & 4.2 & 314 & 6.8 & 343 & 3.5 & 350 & 7.7 & 346 & 0.9 & -5 & 1.7 & 10 & 0.2 & 31 & 2.6 & 13 \\
\hline \multirow[t]{3}{*}{6} & 12 & 0.6 & 244 & 3.9 & 299 & 0.6 & 166 & 3.3 & 303 & 3.6 & 358 & 7.8 & 333 & 0.1 & -78 & -0.6 & 3 & 3.1 & 114 & 3.9 & 33 \\
\hline & 8 & 1.6 & 255 & 5.2 & 311 & 0.4 & 264 & 3.4 & 309 & 3.5 & 350 & 7.7 & 336 & -1.2 & 9 & -1.8 & -1 & 1.9 & 95 & 2.5 & 26 \\
\hline & 4 & 2.0 & 247 & 5.4 & 310 & 1.4 & 304 & 4.3 & 322 & 3.2 & 340 & 7.6 & 340 & -0.5 & 57 & -1.2 & 12 & 1.2 & 93 & 2.2 & 30 \\
\hline \multirow[t]{3}{*}{7} & 12 & 0.6 & 339 & 1.3 & 14 & 0.5 & 321 & 1.0 & 331 & 4.0 & 350 & 6.8 & 345 & -0.2 & -18 & -0.2 & -43 & 3.3 & 11 & 5.6 & -29 \\
\hline & 8 & 2.2 & 300 & 2.7 & 291 & 0.5 & 319 & 1.1 & 332 & 3.7 & 338 & 6.8 & 348 & -1.7 & 20 & -1.7 & 41 & 1.5 & 39 & 4.1 & 57 \\
\hline & 4 & 2.4 & 306 & 3.7 & 314 & 2.6 & 318 & 5.6 & 339 & 3.4 & 322 & 6.9 & 349 & 0.2 & 11 & 1.8 & 26 & 1.0 & 15 & 3.1 & 35 \\
\hline \multirow[t]{3}{*}{8} & 12 & 1.8 & 202 & 2.2 & 234 & 0.7 & 328 & 0.9 & 324 & 4.6 & 336 & 7.7 & 344 & -1.1 & 126 & -1.3 & 90 & 2.8 & 134 & 5.4 & 110 \\
\hline & 8 & 0.8 & 222 & 4.2 & 249 & 0.7 & 327 & 0.9 & 323 & 4.6 & 332 & 7.5 & 347 & -0.2 & 105 & -3.4 & 75 & 3.8 & 110 & 3.3 & 99 \\
\hline & 4 & 2.0 & 281 & 4.0 & 280 & 2.0 & 325 & 2.5 & 320 & 4.5 & 325 & 7.3 & 349 & 0 & 45 & -1.5 & 40 & 2.5 & 44 & 3.2 & 69 \\
\hline \multirow[t]{3}{*}{ Mean } & 12 & 1.6 & & 3.0 & & 1.3 & & 2.4 & & 3.9 & & 7.4 & & -0.3 & 7 & -0.6 & 13 & 2.3 & 74 & 4.4 & 32 \\
\hline & 8 & 2.1 & & 4.3 & & 1.3 & & 2.6 & & 3.9 & & 7.4 & & -0.7 & 31 & -1.6 & 30 & 1.8 & 68 & 3.1 & 48 \\
\hline & 4 & 2.4 & & 4.6 & & 2.6 & & 4.8 & & 3.7 & & 7.4 & & 0.1 & 27 & 0.2 & 22 & 1.2 & 46 & 2.8 & 37 \\
\hline
\end{tabular}



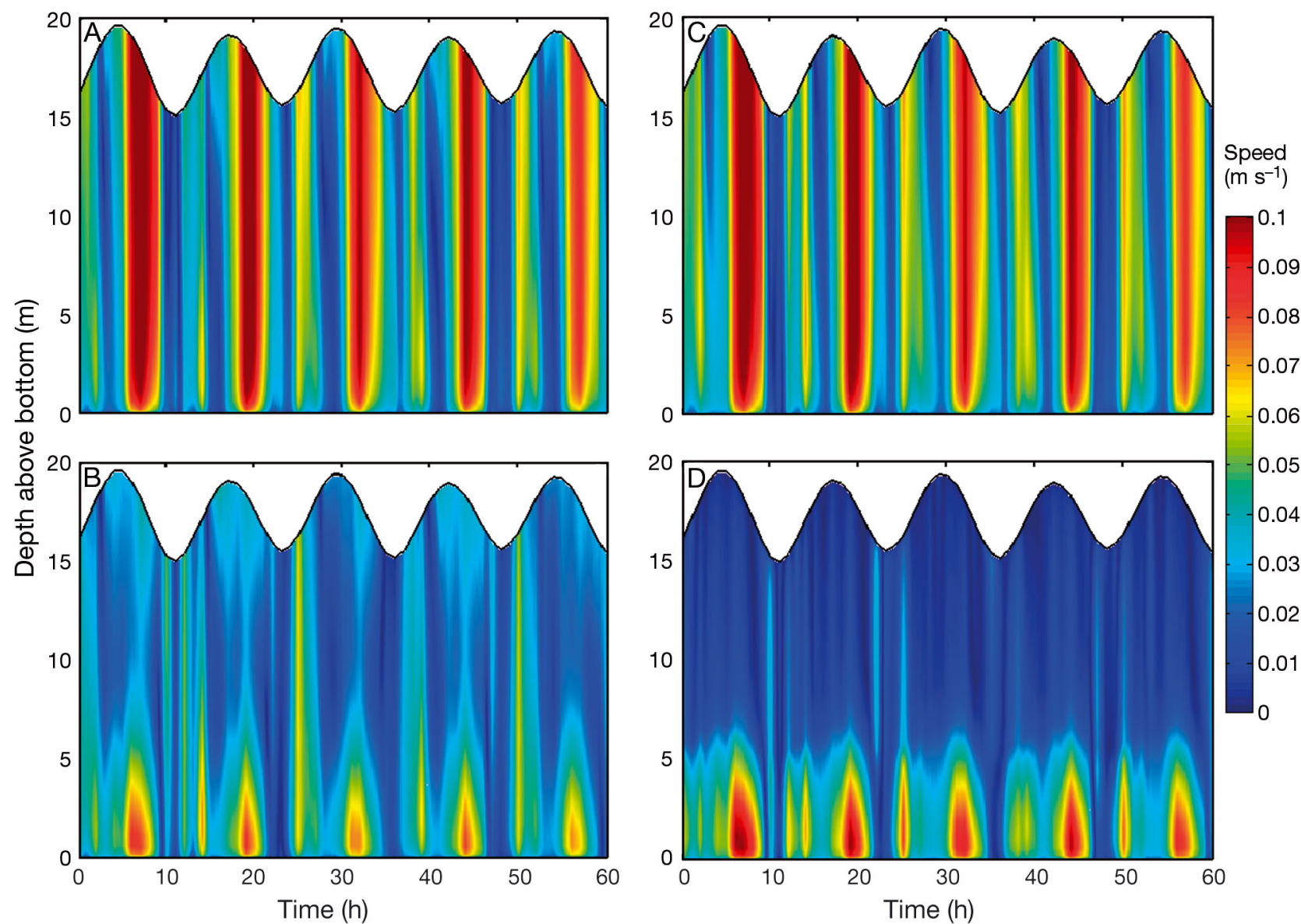

Fig. 5. Vertical distributions of tidal speeds from models (A) without and (B) with cage effect at the edge of the fish farm (see Site 6 in Fig. 1C), and (C) without and (D) with cage effect in the interior of the fish farm (see Site 8 in Fig. 1C)

changes in tidal speed in the bottom layers are greater inside the farm than at the edge. Compared to Fig. 2, the tidal speeds modelled with the fish cages included are reduced too much in the lower layer. This is likely because the vertical variation in the drag is not included in this study.

To show horizontal changes in the tidal current fields due to the presence of the fish cages, we plotted current fields in the mid ebb tide at the surface and bottom layers from model results obtained with and without cage effect (Fig. 6). The time step at mid ebb tide was selected since the ebb tidal current is stronger than the flood (Fig. 5). The tidal current velocity in the surface layer in the model with the cage effect (Fig. 6B) is decreased compared to that in the model without (Fig. 6A), not only in the cage area, but also in the upstream and downstream regions. The decreased magnitude of the tidal speed in the cage area is more pronounced than that in the upstream and downstream areas. In contrast, the tidal velocity increases in the northwestern and southeastern areas of the farm, and the increase in magnitude even reaches about $50 \%$ in the northwest coastal water, from 0.1 to $0.2 \mathrm{~m} \mathrm{~s}^{-1}$. This increase could be due to the cages blocking the passage of the water or the Bernoulli Effect, resulting from the presence of the cages. The directions of the tidal currents also change in the cage area and the areas around the cages. A significant change of direction occurs downstream, where the ebb flow moves from southwest to southeast due to the presence of the cages. At the southeast corner of the farm, the tidal current changes direction along the edge of the farm.

In the bottom layer (about $1 \mathrm{~m}$ above the seabed), the tidal speed in the model with the cage effect increases in the cage area from about 0.1 to $0.2 \mathrm{~m} \mathrm{~s}^{-1}$ compared to that without, especially at the northwest corner of the farm (Fig. 6C,D). Additionally, a clear increase in the tidal velocity occurs in the southwest coastal water. However, tidal velocity decreases in both the upstream and downstream areas. The flow direction is significantly changed in the immediate upstream area, where the direction clearly moves from southwest to southeast along the edge of the farm. 


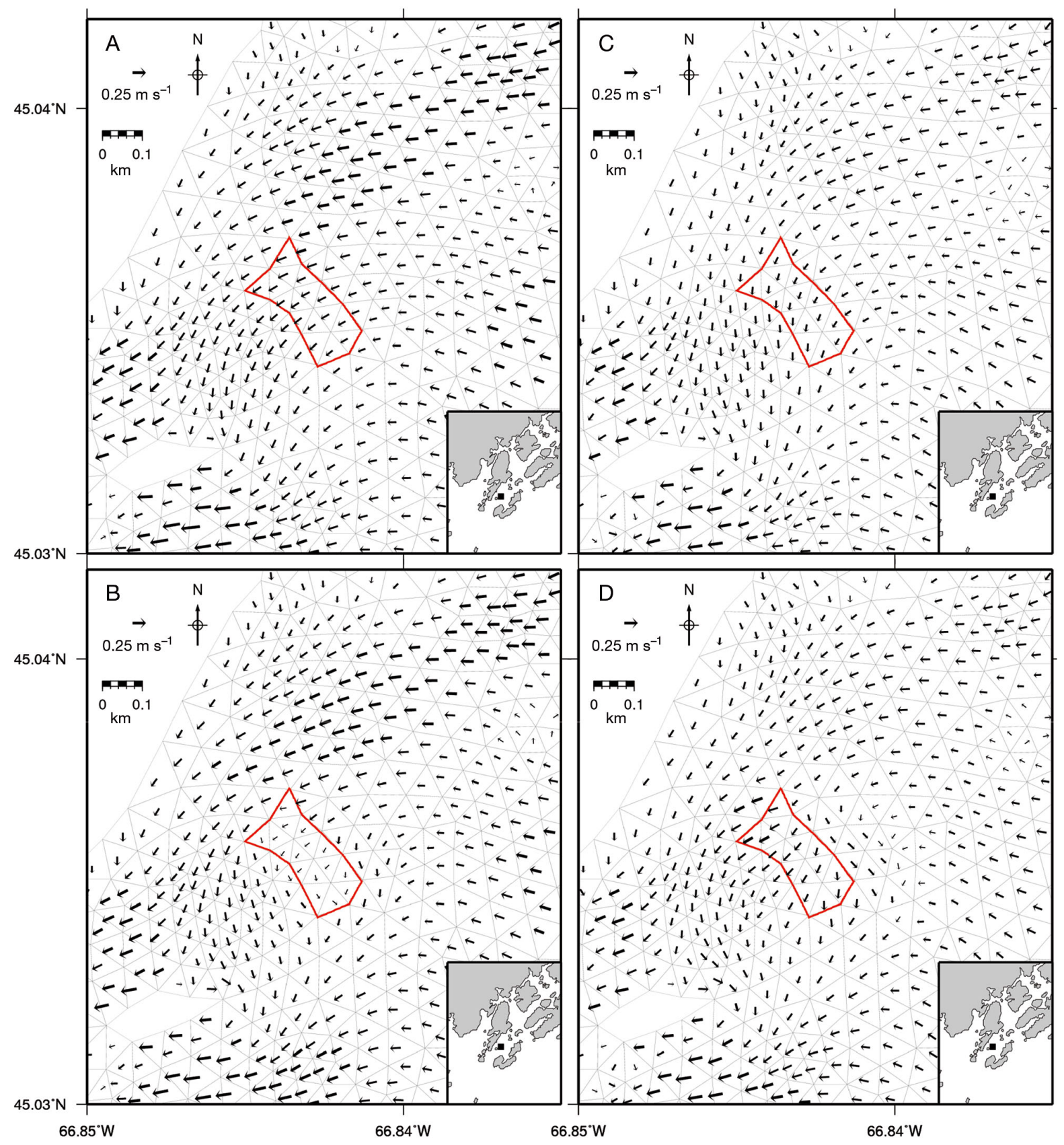

Fig. 6. Modelled current velocity fields at mid ebb tide $(A, C)$ without and $(B, D)$ with cage effect around Bliss Harbour fish farm (red outline, Fig. 1C). (A,B) Results for the surface layer (12 $\mathrm{m}$ above the seabed); (C,D) results for the bottom layer (1 $\mathrm{m}$ above the seabed)

\section{Sensitivity study}

The model results presented indicate that the presence of fish cages blocks water flowing through them and enhances tidal velocity beneath the cages, which potentially changes the erosion of the sediment beneath the cages. In this section, we will examine the sensitivity of the changes in the tidal flow and the erosion properties of the sediment to 2 model parameters. One is the drag coefficient of the cages and the other is the height of the cages. The relative difference between the modelled tidal speed obtained with and without the cage effect is defined as:

$$
R_{u}=\frac{U_{1}-U_{0}}{U_{0}} \times 100 \%
$$

where $U$ is the mean speed at $1 \mathrm{~m}$ above the seabed averaged over tidal cycles and the area beneath the 
fish farm. Subscripts 1 and 0 stand for the cases with and without cage effect, respectively. $U$ is defined as:

$$
U=\frac{1}{T} \int\left[\frac{1}{A} \iint|u| \cdot \mathrm{d} x \mathrm{~d} y\right] \mathrm{d} t
$$

where $T$ is the averaging period $(T=29 \mathrm{~d}), A$ is the area beneath the fish farm and $|u|$ is the instantaneous tidal speed.

Similarly, the relative change in the erosion rate due to the tidal flow is defined as:

$$
R_{\mathrm{e}}=\frac{D_{\mathrm{e} 1}-D_{\mathrm{e} 0}}{D_{\mathrm{e} 0}} \times 100 \%
$$

where $D_{\mathrm{e}}$ is the erosion rate $\left(\mathrm{m} \mathrm{s}^{-1}\right)$. Subscripts 1 and 0 indicate the case with and without cage effect, respectively. $D_{\mathrm{e}}$ is defined as:

$$
D_{\mathrm{e}}=\frac{1}{\rho_{\mathrm{s}}} \frac{1}{T} \int\left[\frac{1}{A} \iint E \cdot \mathrm{d} x \mathrm{~d} y\right] \mathrm{d} t
$$

where $\rho_{\mathrm{s}}$ is the dry density of sediment $\left(\rho_{\mathrm{s}}=2650 \mathrm{~kg}\right.$ $\mathrm{m}^{-3}$ ) and $E$ is the erosion flux $\left(\mathrm{kg} \mathrm{m}^{-2} \mathrm{~s}^{-1}\right)$, which is a function of the bottom shear stress. In general, transport of sediment is mainly controlled by 2 parameters. One is the critical erosion shear stress, and the other is the shear stress of the bottom current. The former parameter is related to the physical-biological-chemical properties of the sediment and, in many cases, is site-specific (Amos et al. 1988, 1992, Sutherland et al. 1998). The latter is mainly related to the intensity of hydrodynamic processes, for instance, waves, tides and currents. The sediment is likely to be eroded when the bottom shear stress is larger than the critical erosion shear stress. In this study, a formula from Cromey et al. (2002b) is used:

$$
E=M\left(\frac{\tau-\tau_{\mathrm{C}}}{\tau_{\mathrm{C}}}\right)
$$

where $M$ is an erosion constant $\left(\mathrm{kg} \mathrm{m}^{-2} \mathrm{~s}^{-1}\right), \tau_{\mathrm{c}}$ is the critical erosion shear stress and $\tau$ is the instantaneous bed shear stress, which is written as:

$$
\tau=\rho c_{\mathrm{d}}|u|^{2}
$$

where $\rho$ is sea water density and $c_{\mathrm{d}}$ is the bottom drag coefficient.

In addition to waste deposits from the farm, the sediment beneath the fish cages usually includes other biological and chemical substances, such as biofouling, residues of therapeutic agents and trace metals (Smith et al. 2005, Yeats et al. 2005, Environment Canada 2009, Milligan \& Law 2013). The complex composition significantly influences the physical characteristics of the sediment and thus its transport properties, including erosion, deposition, flocculation and
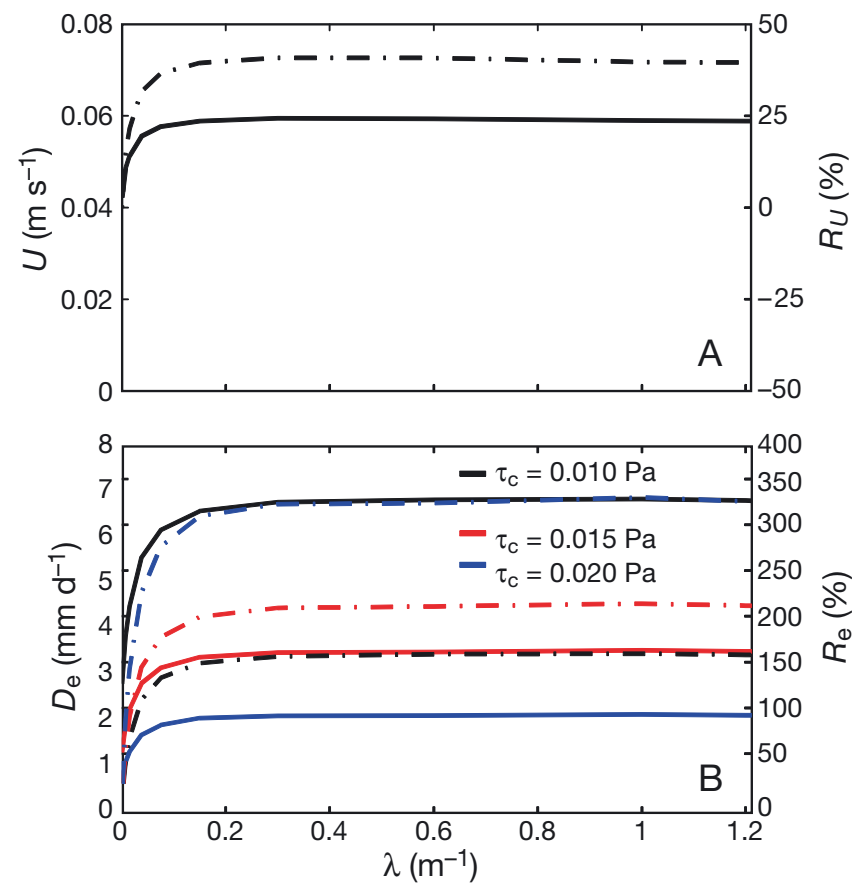

Fig. 7. (A) Bottom speed $(U)$ and (B) erosion rate $\left(D_{\mathrm{e}}\right)$ versus the drag coefficient $(\lambda)$ of the fish cages. Solid line: bottom speed/erosion (scale on left); dashed line: relative ratio $\left(R_{U}\right.$ and $R_{\mathrm{e}}$ ) (scale on right)

consolidation (Amos et al. 1988, 1992, Sutherland et al. 1998, Cromey et al. 2002b, Gyllenhammar \& Hakanson 2005, Sutherland et al. 2006, Giles et al. 2009). The determination of the parameters $M$ and $\tau_{\mathrm{c}}$ is therefore difficult in the absence of site-specific erosion parameters from in situ observations. Since we focus on the effects of the variations in the drag coefficient and the height of the fish cages, the values of the 2 parameters are drawn directly from the study of Cromey et al. (2002b): $M=7 \times 10^{-7} \mathrm{~kg} \mathrm{~m}^{-2} \mathrm{~s}^{-1}$ and $\tau_{\mathrm{c}}=$ $0.010,0.015$ and $0.020 \mathrm{~Pa}$, representing different erosion levels of the bottom sediment. Since we focus on the overall effect of the fish farm, the variation in the erosion parameters at specific cages is ignored.

\section{Drag coefficient}

Sensitivities of the bottom current and the erosion rate to the drag coefficient $(\lambda)$ are shown in Fig. 7 . In the absence of cages, the speed of the bottom current increases from $0.04 \mathrm{~m} \mathrm{~s}^{-1}$ at $\lambda=0.0 \mathrm{~m}^{-1}$ to the peak value of $0.06 \mathrm{~m} \mathrm{~s}^{-1}$ at $\lambda=0.4 \mathrm{~m}^{-1}$, and the increase rate reaches $40 \%$. After this point, the speed changes little despite further increases in the drag coefficient. Similarly, the erosion rate is proportional to $\lambda$ before reaching the peak value and then does not vary much 


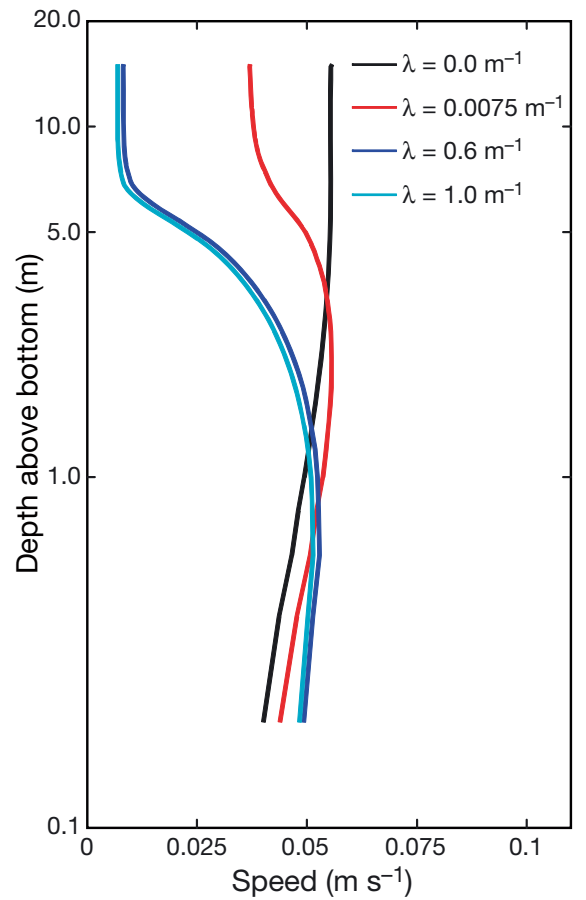

Fig. 8. Vertical distributions of tidal cycle averaged speeds with different cage drags $(\lambda)$

with further increases in the drag coefficient. Sediment erosion is strongly sensitive to the critical shear stress $\left(\tau_{c}\right)$. The maximum erosion rate decreases from $6.6 \mathrm{~mm} \mathrm{~d}^{-1}$ when $\tau_{\mathrm{c}}=0.010$ Pa to $1.9 \mathrm{~mm} \mathrm{~d}^{-1}$ when $\tau_{\mathrm{c}}=$ $0.020 \mathrm{~Pa}$, and the relative change rate increases from 160 to $330 \%$. The vertical distributions of the velocity averaged over the farm with different drag coefficients are plotted in Fig. 8. Compared to the model results obtained without the cage effect, the tidal speeds are clearly reduced in the upper layer where the drag is applied. The magnitude of the reduction increases as the drag increases. The tidal velocity increases from the bottom of the cages to the depth where the maximum velocity occurs (from 1 to $5 \mathrm{~m}$ above the seabed), and then decreases due to the effect of the bottom boundary. The vertical profiles of velocity in the model runs with drag effect are different from those without the cage effect. The shape of the profile appears to be related to the velocity at the bottom of the cages. This means that the presence of the fish cages changes the structure of the velocity between the seabed and the fish cages. A detailed mechanism of these changes will be presented in the future.

\section{Cage height}

The speed beneath the fish farm first increases with increasing cage height and then decreases after reaching the peak value (Fig. 9A). In the absence of the cages $\left(H / H_{0}=0.0\right.$, where $H$ is the cage height and $H_{0}$ is the mean water depth; at the fish farm, $H_{0}=$ $17.5 \mathrm{~m}$ ), tidal velocity is $0.04 \mathrm{~m} \mathrm{~s}^{-1}$, and reaches a maximum of $0.060 \mathrm{~m} \mathrm{~s}^{-1}$ when $H / H_{0}$ is about 0.50 . With further increase in cage height, tidal speed decreases continuously and reaches $0.025 \mathrm{~m} \mathrm{~s}^{-1}$ when the fish cages cover most of the water column $\left(H / H_{0}\right.$ $=0.9$ ). A similar relation can be found between cage height and erosion rate (Fig. 9B). The increase reaches a maximum when the height of the cages is about half of the water depth. With an increase in the critical shear stress from 0.010 to $0.020 \mathrm{~Pa}$, the maximum erosion rate decreases from 7.0 to $2.0 \mathrm{~mm} \mathrm{~d}^{-1}$, and the relative change rate increases from 180 to $380 \%$. This means that an increase in the velocity due to fish cages plays a more important role for the bottom sediment as a result of the higher critical erosion shear stress. When the coverage of cages exceeds $85 \%$ of the water column $\left(H / H_{0}>0.85\right)$, however, the erosion activity nearly stops. The vertical distributions of the tidal speed with different cage heights are shown in Fig. 10. The vertical distributions of the tidal velocity, including shapes and magnitudes, are strongly sensitive to variations in cage height. For the case $H=2.0 \mathrm{~m}$, the modelled tidal

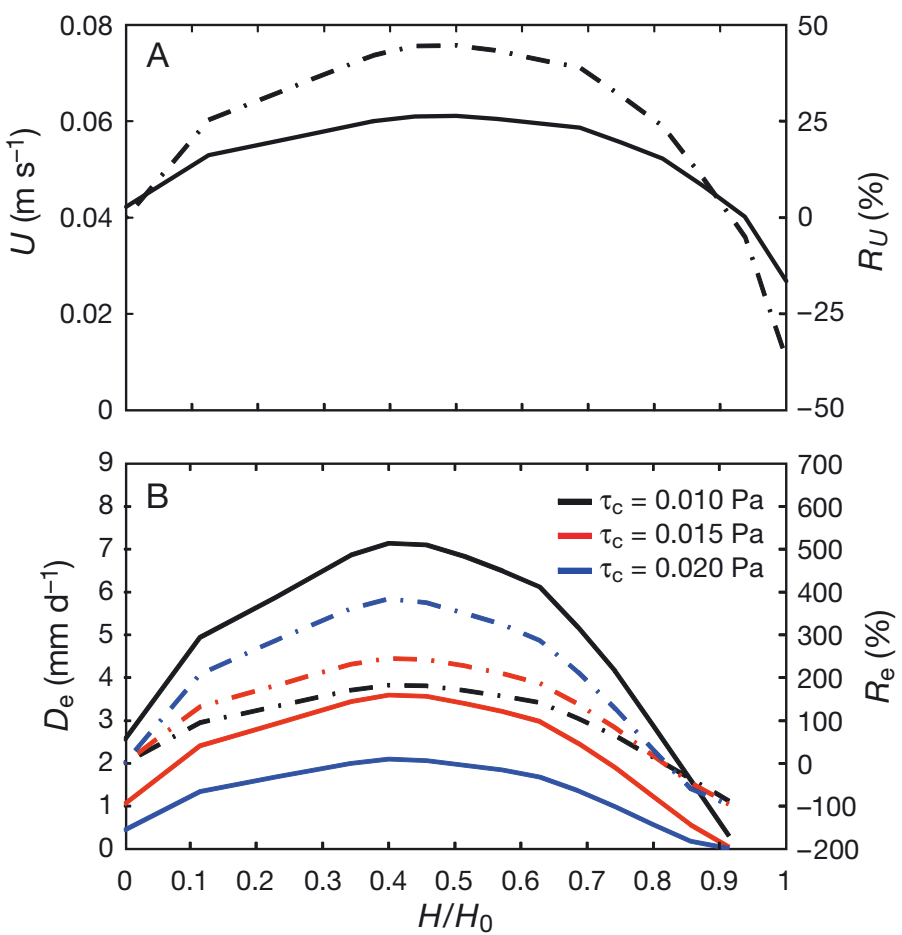

Fig. 9. (A) Bottom speed $(U)$ and (B) erosion rate $\left(D_{\mathrm{e}}\right)$ versus cage height. Solid line: bottom speed/erosion (scale on left); dashed line: relative ratio ( $R_{U}$ and $R_{\mathrm{e}}$ ) (scale on right). $H$ indicates the cage height and $H_{0}$ indicates the mean water depth $\left(H_{0}=17.5 \mathrm{~m}\right)$ 


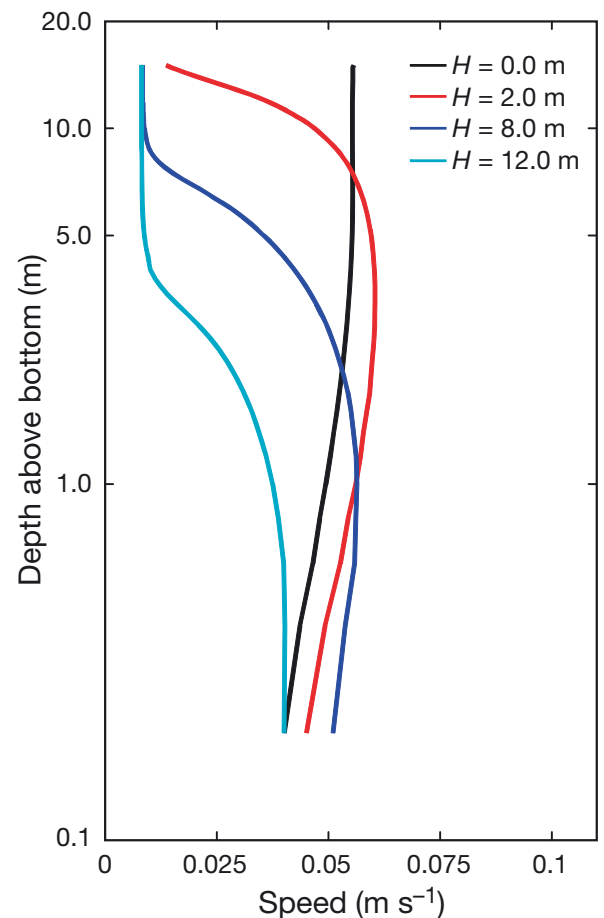

Fig. 10. Vertical distributions of tidal cycle averaged speeds with different cage heights $(H)$

speed in the bottom layer up to $5.0 \mathrm{~m}$ exceeds that of the case without the cage effect. For $H=12.0 \mathrm{~m}$, however, the tidal speed is lower than that in the absence of cages within the whole water column.

\section{DISCUSSION}

Impacts of aquaculture on the local current field and the erosion of the bottom sediment have been investigated in the present study using a 3-D community model, FVCOM, in which the effect of the cages is simulated by an extra friction term defined as a function of water velocity and 2 cage-dependent parameters, the drag coefficient and the cage height. The method was applied to a fish farm off southwest New Brunswick and the model results are compared to independent current meter data collected in and around the farm. The value of the drag coefficient is calibrated with field current meter data. The model results show that the existence of fish cages is able to significantly change the local current field and the erosion of the bottom sediment beneath the cages. Optimal netting and height of the fish cages could significantly increase the water velocity and bottom shear stress, which could then speed up the removal of waste. As a preliminary study, several aspects of the model are simplified or ignored. For instance, the present study ignores the variation in the drag coefficient associated with the flow intensity, the mesh size of the cages and even the density of the fish in the cages. In this study, only the tidal current is discussed. Many other factors, such as wind, waves and density stratification, are ignored. These omissions clearly idealize the complexity of the effects resulting from the presence of the fish cages. Additionally, there is, as always, a need for improved horizontal and vertical resolutions, so that the effect of a single cage and interactions between cages are better represented numerically, and the changes in velocity in the surface and bottom layers are adequately reflected in the model.

Acknowledgements. This work was supported by the Department of Fisheries and Oceans Canada Program for Aquaculture Regulatory Research (PARR). We thank C. Hannah and P. Smith for their many helpful suggestions. B. Greenan and T. Milligan read an early version of the paper and gave helpful comments and suggestions for improvement. The constructive comments by 4 anonymous reviewers are greatly appreciated.

\section{LITERATURE CITED}

Ali A, Thiem Ø, Berntsen J (2011) Numerical modelling of organic waste dispersion from fjord located fish farms. Ocean Dyn 61:977-989

> Amos CL, Van Wagoner NA, Daborn GR (1988) The influence of subaerial exposure on the bulk properties of finegrained intertidal sediment from Minas Basin, Bay of Fundy. Estuar Coast Shelf Sci 27:1-13

$>$ Amos CL, Daborn GR, Christian HA, Atkinson A, Robertson A (1992) In situ erosion measurements on fine-grained sediments from the Bay of Fundy. Mar Geol 108:175-196

Andréfouët S, Ouillon S, Brinkman R, Falter J and others (2006) Review of solutions for 3D hydrodynamic modeling applied to aquaculture in South Pacific atoll lagoons. Mar Pollut Bull 52:1138-1155

Beveridge MCM (1984) Cage and pen fish farming. Carrying capacity models and environmental impact. FAO Fish Tech Pap 255

Chen C, Liu H, Beardsley RC (2003) An unstructured grid, finite-volume, three-dimensional, primitive equations ocean model: application to coastal ocean and estuaries. J Atmos Ocean Technol 20:159-186

Chen C, Huang H, Beardsley RC, Liu H, Xu Q, Cowles G (2007) A finite volume numerical approach for coastal ocean circulation studies: comparisons with finite difference models. J Geophys Res 112:C03018, doi:10.1029/ 2006JC003485

Cowles GW, Lentz SJ, Chen C, Xu Q, Beardsley RC (2008) Comparison of observed and model-computed low frequency circulation and hydrography on the New England Shelf. J Geophys Res 113:C09015, doi:10.1029/ 2007JC004394

Cromey CJ, Nickell TD, Black KD (2002a) DEPOMODmodelling the deposition and biological effects of waste solids from marine cage farms. Aquaculture 214:211-239 Cromey CJ, Nickell TD, Black KD, Provost PG, Griffiths CR 
(2002b) Validation of a fish farm waste resuspension model by use of a particulate tracer discharged from a point source in a coastal environment. Estuaries 25: 916-929

- DeCew J, Tsukrov I, Risso A, Swift MR, Celikkol B (2010) Modelling of dynamic behavior of a single-point moored submersible fish cage under currents. Aquacult Eng 43: 38-45

> Doglioli AM, Magnldi MG, Vezzulli L, Tucci S (2004) Development of a numerical model to study the dispersion of wastes coming from a marine fish farm in the Ligurian Sea (Western Mediterranean). Aquaculture 231:215-235

Dong G, Xu T, Zhao Y, Li Y, Gui F (2010) Numerical simulation of hydrodynamic behaviour of gravity cage in irregular waves. Aquacult Eng 42:90-101

> Dudley RW, Panchang VG, Newell CR (2000) Application of a comprehensive modelling strategy for the management of net-pen aquaculture waste transport. Aquaculture 187:319-349

Dupont F, Hannah CG, Greenberg DA, Cherniawsky JY, Naimie CE (2002) Modelling system for tides for the Northwest Atlantic Coastal Ocean. Can Tech Rep Hydrogr Ocean Sci 221

Environment Canada (2009) Organic waste and feed deposits on bottom sediments from aquaculture operations: scientific assessment and guidance. Ecosystem health: science-based solutions report No. 1-14. National Guidance and Standards Office, Environment Canada

Fernandes M, Angove M, Sedawie T, Cheshire A (2007) Dissolved nutrient release from solid wastes of southern bluefin tuna (Thunnus maccoyii, Castelnau) aquaculture. Aquacult Res 38:388-397

Fredriksson DW, Swift MR, Irish JD, Tsukrov I, Celikol B (2003) Fish cage mooring system dynamics using physical and numerical models with field measurements. Aquacult Eng 27:117-146

Fredriksson DW, DeCew JC, Tsukrov I, Swift MR, Irish JD (2007) Development of large fish farm numerical modeling techniques with in situ mooring tension comparisons. Aquacult Eng 36:137-148

> Gao G, Chen C, Qi J, Beardsley RC (2011) An unstructuredgrid, finite-volume sea ice model: development, validation and application. J Geophys Res 116:C00D04, doi: 10.1029/2010JC006688

Giles H, Broekhuizen N, Bryan KR, Pilditch CA (2009) Modelling the dispersal of biodeposits from mussel farms: the importance of simulating biodeposit erosion and decay. Aquaculture 291:168-178

Grant J, Bacher C (2001) A numerical model of flow modification induced by suspended aquaculture in a Chinese bay. Can J Fish Aquat Sci 58:1003-1011

Gyllenhammar A, Hakanson L (2005) Environmental consequence analyses of fish farm emissions related to different scales and exemplified by data from the Baltica review. Mar Environ Res 60:211-243

Hasegawa D, Sheng J, Greenberg DA, Thompson KR (2011) Far-field effects of tidal energy extraction in the Minas Passage on tidal circulation in the Bay of Fundy and Gulf of Maine using a nested grid coastal circulation model. Ocean Dyn 61:1845-1868

> Henderson A, Gamito S, Karakassis I, Pederson P, Smaal A (2001) Use of hydrodynamic and benthic models for managing environmental impacts of marine aquaculture. J Appl Ichthyol 17:163-172

> Hevia M, Rosenthal H, Gowen RJ (1996) Modelling benthic deposition under fish cages. J Appl Ichthyol 12:71-74

- Huang C, Tang H, Liu T (2008) Effects of waves and currents on gravity-type cages in the open sea. Aquacult Eng 38: $105-116$

Inoue H (1972) On water exchange in a net cage stocked with the fish Hamachi. Bull Jpn Soc Sci Fish 38:167-176

Lee C, Kim Y, Lee G, Choe M, Lee M, Koo K (2008) Dynamic simulation of a fish cage system subjected to currents and waves. Ocean Eng 35:1521-1532

Milligan TG, Law BA (2013) Contaminants at the sedimentwater interface: implications for environmental impact assessment and effects monitoring. Environ Sci Technol 47:5828-5834

Moreno Navas J, Telfer TC, Ross LG (2011) Application of 3D hydrodynamic and particle tracking models for better environmental management of finfish culture. Cont Shelf Res 31:675-684

Page FH, Losier R, McCurdy P, Greenberg DA, Chaffey J (2005) Dissolved oxygen and salmon cage culture in the southwestern New Brunswick portion of the Bay of Fundy. In: Hargrave BT (ed) Environmental effects of marine finfish aquaculture. Handbook of Environmental Chemistry, Vol 5M. Springer, Berlin, p 1-28

Panchang V, Cheng G, Newell C (1997) Modelling hydrodynamics and aquaculture waste transport in coastal Maine. Estuaries 20:14-41

> Pawlowicz R, Beardsley B, Lentz S (2002) Classical tidal harmonic analysis including error estimates in MATLAB using T-TIDE. Comput Geosci 28:929-937

Rasmussen M, McLean E (2004) Comparison of two different methods for evaluating the hydrodynamic performance of an industrial-scale fish-rearing unit. Aquaculture 242: 397-416

Sanz-Lázaro C, Belando MD, Marín-Guirao L, NavarreteMier F, Marín A (2011) Relationship between sedimentation rates and benthic impact on Maërl beds derived fish farming in the Mediterranean. Mar Environ Res 71: 22-30

Silvert W, Sowles JW (1996) Modelling environmental impacts of marine finfish aquaculture. J Appl Ichthyology 12:75-81

> Skogen M, Eknes M, Asplin CA, Sandvik AD (2009) Modelling the environmental effects of fish farming in a Norwegian fjord. Aquaculture 298:70-75

Smith JN, Yeats PA, Milligan TG (2005) Sediment geochronologies for fish farm contaminants in sediments from Limekiln Bay, Bay of Fundy. In: Hargrave BT (ed) Environmental effects of marine finfish aquaculture. Handbook of environmental chemistry, Vol 5M. Springer, Berlin, p 221-238

Sutherland TF, Amos CL, Grant J (1998) The effect of buoyant biofilms on the erodibility of sublittoral sediment of a temperate microtidal estuary. Limnol Oceanogr 43: 225-235

Sutherland TF, Amos CL, Ridley C, Droppo IG, Petersen SA (2006) The settling behaviour and benthic transport of fish feed pellets under steady flows. Estuaries Coasts 29: 810-819

Wu Y, Chaffey J, Greenberg DA, Colbo K, Smith PC (2011) Tidally-induced sediment transport patterns in the upper Bay of Fundy: a numerical study. Cont Shelf Res 31: 2041-2053

Yeats PA, Milligan TG, Sutherland TF, Robinson SMC, Smith JN, Lawton P, Levings CD (2005) Lithium normalized zinc and copper concentrations in sediments as measures or trace metal enrichment due to salmon aquaculture. In: Hargrave BT (ed) Environmental effects of marine finfish aquaculture. Handbook of environmental chemistry, Vol 5M. Springer, Berlin, p 207-220 